\title{
Poor medical care for people with migraine in Europe - evidence from the Eurolight study
}

\author{
Zaza Katsarava ${ }^{1 *}$, Maka Mania², Christian Lampl ${ }^{3}$, Johanna Herberhold ${ }^{4}$ and Timothy J. Steiner ${ }^{5,6}$
}

\begin{abstract}
Background: Migraine is prevalent everywhere, and disabling. It is also neglected: consequently, it is underdiagnosed and undertreated. We analysed data from the Eurolight study on consultations and utilization of migraine-specific medications as indicators of adequacy of medical care in Europe.
\end{abstract}

Methods: Eurolight was a cross-sectional questionnaire-based survey in 10 European countries. Sampling was population-based in six (Germany, Italy, Lithuania, Luxembourg, Netherlands, Spain) and from consecutive patients attending general practitioners (GPs) for any reason in three (Austria, France, UK). Additional samples in Netherlands and Spain, and the only sample from Ireland, were recruited by lay headache organisations. We recorded migraine prevalence and frequency, and utilization of medical services and medications (acute and preventative).

Results: Among 9247 participants (mean age $43.9 \pm 13.9$ years, M/F ratio 1:1.4), 3466 (37.6\%) were diagnosed with migraine (definite or probable). Of these, 1175 (33.8\%) reported frequent migraine (> 5 days/month) and might clearly expect benefit from, and therefore had need of, preventative medication. In population-based samples, minorities of participants with migraine had seen a GP (9.5-18.0\%) or specialist (3.1-15.0\%), and smaller minorities received adequate treatment: triptans 3.4-11.0\%, with Spain outlying at 22.4\%; preventative medication (1.6-6.4\% of those eligible, with Spain again outlying at 13.7\%). Proportions were greater in GP-based samples (13.6-24.5\% using triptans, 4.4-9.1\% on preventative medication) and among those from lay organisations (46.2-68.2\% and 16.0-41.7\%). Participants with migraine who had consulted specialists (3.1-33.8\%) were receiving the best care by these indicators; those treated by GPs (9.5-29.6\%) fared less well, and those dependent on self-medication (48.0-84.2\%) were, apparently, inadequately treated.

Conclusion: In wealthy European countries, too few people with migraine consult physicians, with proportionately too many of these seeing specialists, and migraine-specific medications are used inadequately even among those who do. These findings represent yet another call for action in Europe to improve care for people with headache. Education of both health-care providers and the public should be central to this action.

Keywords: Headache, Migraine, Impact, Health care, Health policy, Europe, Eurolight project, Global campaign against headache

\footnotetext{
* Correspondence: Zaza.katsarava@gmail.com

${ }^{1}$ Evangelical Hospital Unna, University of Duisburg-Essen, Essen, Germany

Full list of author information is available at the end of the article
} 


\section{Background}

Headache disorders, including migraine, are extremely common [1]. From a public-health perspective, they are also among the most disabling at population level: according to the Global Burden of Disease (GBD) study, headache disorders collectively are the third highest cause in the world of years of healthy life lost to disability (YLDs), migraine alone being sixth (third in those aged under 50 years) [2-5]. The lost-productivity and consequential financial costs are enormous [6].

It might be expected that headache disorders would, everywhere, be considered important: as a personal medical problem by people directly affected by them, and as a public-health priority by healthcare providers and health policy-makers. The reality is different. People with headache are underdiagnosed and undertreated not only in poorer countries with limited resources and restricted access to medical care but also, evidence indicates, in wealthy Europe and North America [7, 8]. We sought to verify this in Europe by analysing data from the Eurolight study.

Eurolight was an initiative supported by the European Commission Executive Agency for Health and Consumers (EHAC), and a partnership activity within the Global Campaign against Headache $[9,10]$ conducted by Lifting The Burden (LTB), a UK-registered nongovernmental organization in official relations with the World Health Organization [11]. Eurolight gathered data on headache disorders in a cross-sectional survey in 10 countries, which together represented $>60 \%$ of the adult population (18-65 years) of the European Union (EU): Austria, France, Germany, Ireland, Italy, Lithuania, Luxembourg, Netherlands, Spain and United Kingdom (UK) [12]. The survey included diagnostic enquiry regarding primary headaches and further enquiry into headache-attributed burden and utilisation of medical services and medication for headache. Here we present data on consultations and use of migraine-specific acute and preventative medications, and analyse these as indicators of adequacy of medical care for people with migraine in Europe.

\section{Methods}

\section{Ethics}

The National Ethics Committee of Luxembourg gave overall approval of the protocol and provisions for data protection. Further approvals were obtained from national and/or local ethics committees wherever needed, since the methods for recruitment of participants differed between countries. In every country, prospective participants received written information explaining the project and its purpose.

\section{Study design}

The methods of the Eurolight project have been described in detail elsewhere [12], and are summarised here.

Eurolight was a cross-sectional questionnaire-based survey of adults (18-65 years) in the EU, sampling from 10 countries. The sampling and questionnairedistribution methods, summarised in Table 1, varied between countries according to what was feasible [12]: in six countries (Germany, Italy, Lithuania, Luxembourg, Netherlands, Spain), samples were population-based; in three (Austria, France, UK), general practitioners (GPs) recruited consecutive patients attending for any reason. Additional samples in Spain and Netherlands, and the only sample in Ireland, were recruited through lay organisations [12].

The survey used the same structured questionnaire in all countries [13]. It had multiple parts. Demographic enquiry included age, gender, marital status and socioeconomic status. Screening questions for headache (with an enquiry timeframe of the preceding year) were followed, in those responding positively, by headachediagnostic questions based on ICHD-II [14]. To avoid diagnostic confusion, participants identifying more than one headache type were asked to report only on the one that was most bothersome to them. Enquiry into healthcare utilisation entailed questions on use for headache of acute and preventative medications, consultations for headache (yes or no) with nurse, GP, neurologist or headache specialist, investigations for headache (MRI, CT, X-rays of the neck, blood tests, ophthalmic examination), and admissions (number) to hospital because of headache.

\section{Analysis and statistics}

Diagnoses were made from questionnaire responses by computerized algorithm [15]. This first identified, and separated, participants reporting headache on $\geq 15$ days/ month, of whom additional questions had enquired into frequency of acute medication use. Probable medicationoveruse headache $(\mathrm{pMOH})$ was diagnosed when, in addition, simple analgesics were used on $\geq 15$ days/ month or medication including compound analgesics, opioids, triptans and/or ergots was taken on $\geq 10$ days/ month. A diagnosis of $\mathrm{pMOH}$ trumped all other diagnoses. The remainder of this group were diagnosed as "other headache on $\geq 15$ days/month". To all others, who had headache on $<15$ days/month, the algorithm applied ICHD-II criteria for definite migraine, definite tensiontype headache $(\mathrm{TTH})$, probable migraine and probable TTH in that order.

Analysis focused on participants in whom migraine was diagnosed, not distinguishing between those meeting criteria for definite migraine or probable migraine 
Table 1 Summary of sampling and data collection methods in each country [adapted from reference [12]

\begin{tabular}{|c|c|c|c|c|c|}
\hline Country & $\begin{array}{l}\text { Denominator } \\
\text { (n) }\end{array}$ & $\begin{array}{l}\text { Responders } \\
\text { (n) }\end{array}$ & $\begin{array}{l}\text { Responder } \\
\text { proportion (\%) }\end{array}$ & $\begin{array}{l}\text { Gender } \\
\text { (\% female) }\end{array}$ & $\begin{array}{l}\text { Target population and mode of } \\
\text { distribution of questionnaire }\end{array}$ \\
\hline \multicolumn{6}{|c|}{ Studies with a general-population basis } \\
\hline Germany & 3000 & 338 & 11.3 & 57 & $\begin{array}{l}\text { Random general-population sample } \\
\text { from urban and rural areas, contacted } \\
\text { by regular post }\end{array}$ \\
\hline Italy & 3500 & 500 & 14.3 & 58 & $\begin{array}{l}\text { Stratified general-population sample } \\
\text { from urban and rural areas, contacted } \\
\text { by regular post }\end{array}$ \\
\hline Lithuania & 1137 & 616 & 54.2 & 59 & $\begin{array}{l}\text { General-population sample in and } \\
\text { around Kaunas (urban and rural), } \\
\text { contacted by door-to-door cold-calling } \\
\text { and personally interviewed by trained } \\
\text { medical students }\end{array}$ \\
\hline Luxembourg & 6498 & 2023 & 31.1 & 58 & $\begin{array}{l}\text { Stratified general-population sample } \\
\text { contacted by regular post }\end{array}$ \\
\hline Netherlands-population & unknown & 2414 & incalculable & 50 & $\begin{array}{l}\text { Stratified general-population sample } \\
\text { contacted by internet }\end{array}$ \\
\hline Spain-workplace & 1700 & 999 & 58.8 & 59 & $\begin{array}{l}\text { Stratified sample of postal services } \\
\text { employees, contacted by internal post } \\
\text { by occupational health physicians }\end{array}$ \\
\hline \multicolumn{6}{|c|}{ Studies conducted in general practice settings } \\
\hline Austria & unknown, but not > 6000 & 646 & incalculable & 70 & $\begin{array}{l}\text { Consecutive patients consulting GPs or } \\
\text { neurologists for any reason; } \\
\text { questionnaire handed directly }\end{array}$ \\
\hline France & 2400 & 876 & 36.5 & 68 & $\begin{array}{l}\text { Consecutive patients consulting GPs for } \\
\text { any reason; questionnaire handed } \\
\text { directly }\end{array}$ \\
\hline UK & 720 & 128 & $17.8^{*}$ & 65 & $\begin{array}{l}\text { Consecutive patients attending GPs for } \\
\text { any reason; questionnaire handed } \\
\text { directly }\end{array}$ \\
\hline \multicolumn{6}{|c|}{ Studies among members of lay headache organizations } \\
\hline Ireland & members 1500 relatives unknown & $\begin{array}{l}195 \\
73\end{array}$ & $\begin{array}{l}13.0 \\
\text { incalculable }\end{array}$ & 66 & $\begin{array}{l}\text { Members of Migraine Association of } \\
\text { Ireland and their non-biological rela- } \\
\text { tives, contacted by regular post }\end{array}$ \\
\hline Netherlands-lay & members 500 partners unknown & $\begin{array}{l}337 \\
115\end{array}$ & $\begin{array}{l}67.4 \\
\text { incalculable }\end{array}$ & 57 & $\begin{array}{l}\text { Random sample of members of } \\
\text { Nederlandse Vereniging van } \\
\text { Hoofdpijnpatiënten and (where } \\
\text { existing) their non-headache-affected } \\
\text { partners, contacted by regular post }\end{array}$ \\
\hline Spain-lay & 300 & 272 & 90.7 & 62 & $\begin{array}{l}\text { Members of Asociacion Española de } \\
\text { Pacientes con Cefalea (AEPAC) and their } \\
\text { family; questionnaires distributed by } \\
\text { hand via helpers of AEPAC }\end{array}$ \\
\hline
\end{tabular}

$[12,15,16]$. We identified those with migraine on > 5 days/month as clearly eligible for preventative medication. We selected the following as indicators of adequacy of care: a) proportion receiving migraine-specific acute medications (triptans); b) proportion of those clearly eligible receiving any preventative medication; c) proportions receiving medical care through GP or specialist (neurologist or specialist in headache medicine). In our analysis, consultation with specialist(s) trumped consultation with $\mathrm{GP}(\mathrm{s})$.

Statistical analyses were performed using SPSS. We describe categorical variables in terms of frequency (n) and proportions (\%), and continuous variables in terms of means \pm standard deviations (SDs). We used $2 \times 2$ chisquared to compare proportions receiving treatments in specialist and primary care.

\section{Results}

Eurolight collected 9247 correctly completed questionnaires from participants in the 10 countries (mean age $43.9 \pm 13.9$ years, $\mathrm{M} / \mathrm{F}$ ratio $1: 1.4$ [Table 1 ]). The principal results have been reported in detail previously [17]. Here we analysed the data of 3466 people (37.6\%) with migraine (definite or probable) (Table 2). 
Table 2 Sociodemographic features of participants with migraine $(N=3466)$

\begin{tabular}{|c|c|c|c|c|c|}
\hline Country & $n$ & Females (\%) & Age (years) (mean $\pm S D)$ & $\begin{array}{l}\text { Living with spouse } \\
\text { or partner (\%) }\end{array}$ & $\begin{array}{l}\text { Employed or } \\
\text { self-employed (\%) }\end{array}$ \\
\hline \multicolumn{6}{|c|}{ Studies with a general-population basis } \\
\hline Germany & 109 & 67.9 & $41.6 \pm 11.9$ & 57 & 65 \\
\hline Italy & 221 & 70.1 & $40.2 \pm 11.7$ & 94 & 71 \\
\hline Lithuania & 149 & 80.5 & $42.5 \pm 12.3$ & 67 & 66 \\
\hline Luxembourg & 669 & 67.9 & $38.2 \pm 11.2$ & 73 & 69 \\
\hline Netherlands-population & 815 & 60.2 & $40.5 \pm 12.5$ & 68 & 69 \\
\hline Spain-workplace & 401 & 68.6 & $41.7 \pm 11.1$ & 71 & 83 \\
\hline \multicolumn{6}{|c|}{ Studies conducted in health-care settings } \\
\hline Austria & 263 & 81.4 & $44.2 \pm 13.5$ & 74 & 67 \\
\hline France & 337 & 76.0 & $43.1 \pm 13.5$ & 78 & 64 \\
\hline UK & 49 & $100.0 \%$ & $41.7 \pm 16.0$ & 64 & 63 \\
\hline \multicolumn{6}{|c|}{ Studies among members of lay headache organizations } \\
\hline Ireland & 152 & 88.8 & $48.5 \pm 13.1$ & 71 & 59 \\
\hline Netherlands-lay & 195 & 83.1 & $46.5 \pm 10.9$ & 78 & 65 \\
\hline Spain-lay & 106 & 76.4 & $40.8 \pm 11.0$ & 71 & 84 \\
\hline
\end{tabular}

The demography of participants with migraine was broadly similar in all countries: they were on average approximately 40 years old, two thirds or more were female, most were married or living with a partner, and most were employed or self-employed (Table 2). Across countries, one third (1175; 33.8\%) reported frequent migraine ( $>5$ days/month) (Table 3) and therefore had clear need of preventative medication.
Utilisation of migraine-specific medications varied greatly between countries. The ranges were, for triptans, $3.4-68.2 \%$ of all participants with migraine and, for preventative medications, $1.6-41.7 \%$ of those deemed clearly eligible for them. These ranges were considerably distorted by the studies among members of lay headache organisations. In population-based samples, $3.4-22.4 \%$ of participants with migraine used triptans and 1.6$13.7 \%$ of those eligible used preventative medication. In

Table 3 Utilization of medical care by participants with migraine $(\mathrm{N}=3466)$

\begin{tabular}{|c|c|c|c|c|c|c|c|c|}
\hline \multirow[t]{2}{*}{ Country } & \multirow[t]{2}{*}{ N } & \multirow{2}{*}{$\begin{array}{l}\text { Using triptans } \\
\text { (of all with } \\
\text { migraine) n (\%) }\end{array}$} & \multirow{2}{*}{$\begin{array}{l}\text { Migraine on } \\
\geq 5 \text { days/ } \\
\text { month } n \text { (\%) }\end{array}$} & \multirow{2}{*}{$\begin{array}{l}\text { Using preventative } \\
\text { medication (of those } \\
\text { with migraine on } \geq 5 \\
\text { days/month) } \mathrm{n}(\%)\end{array}$} & \multicolumn{4}{|c|}{ Consulting health professionals n (\%) } \\
\hline & & & & & Specialist & $\begin{array}{l}\text { General } \\
\text { practitioner }\end{array}$ & Non-medical & None \\
\hline \multicolumn{9}{|c|}{ Studies with a general-population basis } \\
\hline Germany & 109 & $12(11.0)$ & $42(38.5)$ & $1(2.4)$ & $7(6.4)$ & $14(12.8)$ & $5(4.6)$ & $83(76.1)$ \\
\hline Italy & 221 & $14(6.3)$ & $61(27.6)$ & $1(1.6)$ & $14(6.3)$ & $21(9.5)$ & $15(6.8)$ & $171(77.4)$ \\
\hline Lithuania & 149 & $5(3.4)$ & $62(41.6)$ & $2(3.2)$ & $16(10.7)$ & $23(15.4)$ & $2(1.3)$ & $108(72.5)$ \\
\hline Luxemburg & 669 & $48(7.2)$ & $219(32.7)$ & $10(4.6)$ & $39(5.8)$ & $105(15.7)$ & $27(4.0)$ & $498(74.4)$ \\
\hline Netherlands-population & 815 & $75(9.2)$ & $171(20.8)$ & $11(6.4)$ & $25(3.1)$ & $106(13.0)$ & $36(4.4)$ & $648(79.5)$ \\
\hline Spain-workplace & 401 & $90(22.4)$ & $153(38.2)$ & $21(13.7)$ & $60(15.0)$ & $72(18.0)$ & $28(7.0)$ & $241(60.1)$ \\
\hline \multicolumn{9}{|c|}{ Studies conducted in general practice settings } \\
\hline Austria & 263 & $37(14.1)$ & $106(40.3)$ & 7 (6.6) & $46(17.5)$ & $26(10.0)$ & $14(5.3)$ & $177(67.3)$ \\
\hline France & 337 & $46(13.6)$ & $91(27.0)$ & $4(4.4)$ & $7(2.1)$ & $81(24.0)$ & $22(6.5)$ & $227(67.3)$ \\
\hline UK & 49 & $12(24.5)$ & $22(44.9)$ & $2(9.1)$ & $11(22.4)$ & $7(14.3)$ & $0(0)$ & $31(63.3)$ \\
\hline \multicolumn{9}{|c|}{ Studies among members of lay headache organizations } \\
\hline Ireland & 152 & $94(61.8)$ & $78(51.3)$ & $23(29.5)$ & $34(22.4)$ & 45 (29.6) & $6(3.9)$ & $67(44.1)$ \\
\hline Netherlands-lay & 195 & $133(68.2)$ & $120(61.5)$ & $50(41.7)$ & 66 (33.8) & $26(13.3)$ & $21(11.0)$ & $82(42.1)$ \\
\hline Spain-lay & 106 & $49(46.2)$ & $50(47.2)$ & $8(16.0)$ & 25 (23.6) & $27(25.5)$ & $10(9.4)$ & $44(41.5)$ \\
\hline
\end{tabular}


this group, Spain-workplace was an outlier, with values in each case double those of the next highest, while Lithuania appeared to be an outlier for low use of triptans (3.4\%) and Italy for low use of preventative medication (1.6\% of those eligible) (Table 3). Proportions were higher in GP-based samples (13.6-24.5\% using triptans, $4.4-9.1 \%$ on preventative medication), and much higher among those from lay organisations $(46.2-68.2 \%$ and 16.0-41.7\%) (Table 3).

Proportions of people receiving specific acute or preventative medications did not depend an age or socioeconomic or marital status (data not shown).

These medications were not widely available without prescription; therefore, they were accessible only to a limited extent by people treating themselves or consulting a nurse rather than a physician. With regard to trip$\tan$ use, not only was this highly dependent on consultation with a physician but also the proportions using triptans were greater in those seeing specialists (mean 51.3\%) than in those treated by GPs (mean 35.9\%; chi-squared $=62.1 ; p<0.001$ ) (Fig. 1). Similarly, those clearly eligible to receive preventative medications were more likely to do so from specialists (mean 26.0\%) than from GPs (mean 14.1\%; chi-squared $=10.1 ; \mathrm{p}<0.001$ ) (Fig. 2). Participants with migraine who had consulted specialists (2.1-33.8\% across all studies) were receiving the best care by these indicators; those treated by GPs (9.5-29.6\%) fared less well, and the larger numbers dependent on self-medication (48.0-84.2\%) appeared to be inadequately treated. Probability of consultation was itself highly dependent on the source of the sample (Table 3). In the studies with a general-population basis, a minority of participants $(15.8-33.0 \%)$ had done so: $3.1-15.0 \%$ had consulted a specialist (averaged across countries: 6.8\%), and $9.5-18.0 \%$ had seen a GP (average: 14.4\%). In studies conducted in general practice settings, $26.1-36.7 \%$ of participants had consulted, and in studies among members of lay headache organizations, $47.1-52.0 \%$ had done so, with the ranges for specialist and GP as shown in Table 3. The differences reflect bias in the latter samples.

\section{Discussion}

EU countries represent a relatively wealthy area of the world, albeit with some variation. Our study in 10 of these countries confirms that, even among these, migraine is under-treated. At best in the generalpopulation samples (setting aside Spain-workplace), $26.1 \%$ of those with migraine in Lithuania were consulting a physician for it, triptans were in use by $11.0 \%$ in Germany, and preventative medication by $6.4 \%$, of those who appeared to be clear candidates for it, in Netherlands. At worst, the proportions were as low as $15.8 \%$ consulting (in Italy), 3.4\% using triptans (in Lithuania) and $1.6 \%$ of those eligible using preventative medication (again in Italy). The Spanish workplacebased sample fared better on all counts - 33.0\%, 20.4\% and $13.7 \%$, suggesting facilitated access to health care among this sample of employed people. Contact with GPs, and with specialists more so, was associated with higher use of these medications, which is unsurprising not only because they are in the main prescription-only but also because worse-affected people might be more likely to consult.

The samples recruited by general practitioners, and more so those from lay organisations, showed higher proportions consulting and utilising specific medications, which we attribute to the expected selection bias in these two groups. The latter did better for use of triptans $(60.9 \%$ of those with migraine), but, even among these, fewer than one third (32.7\%) of those clearly eligible were using preventative drugs.

While the proportions in contact with doctors and receiving migraine-specific drugs in this study were selfevidently low, at issue here is what, in a perfect world,

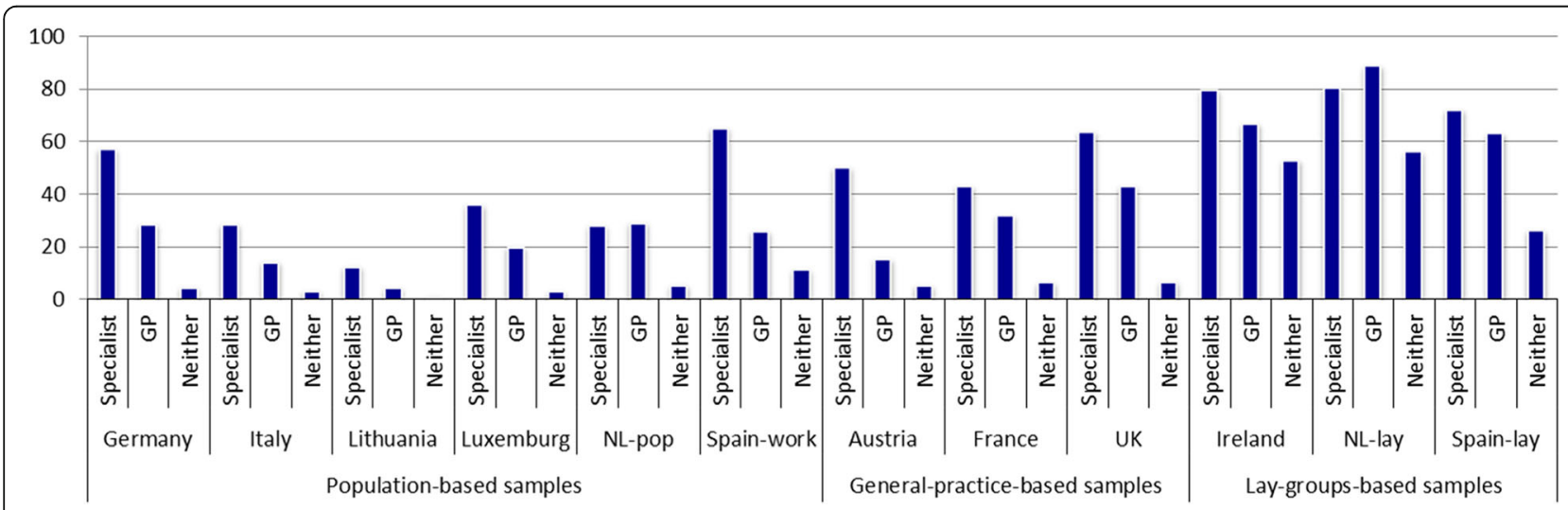

Fig. 1 Proportion (\%) of participants with migraine using triptans, by country and by whom consulting. NL-pop: Netherlands-population; Spain-work: Spain-workplace; NL-lay: Netherlands-lay 


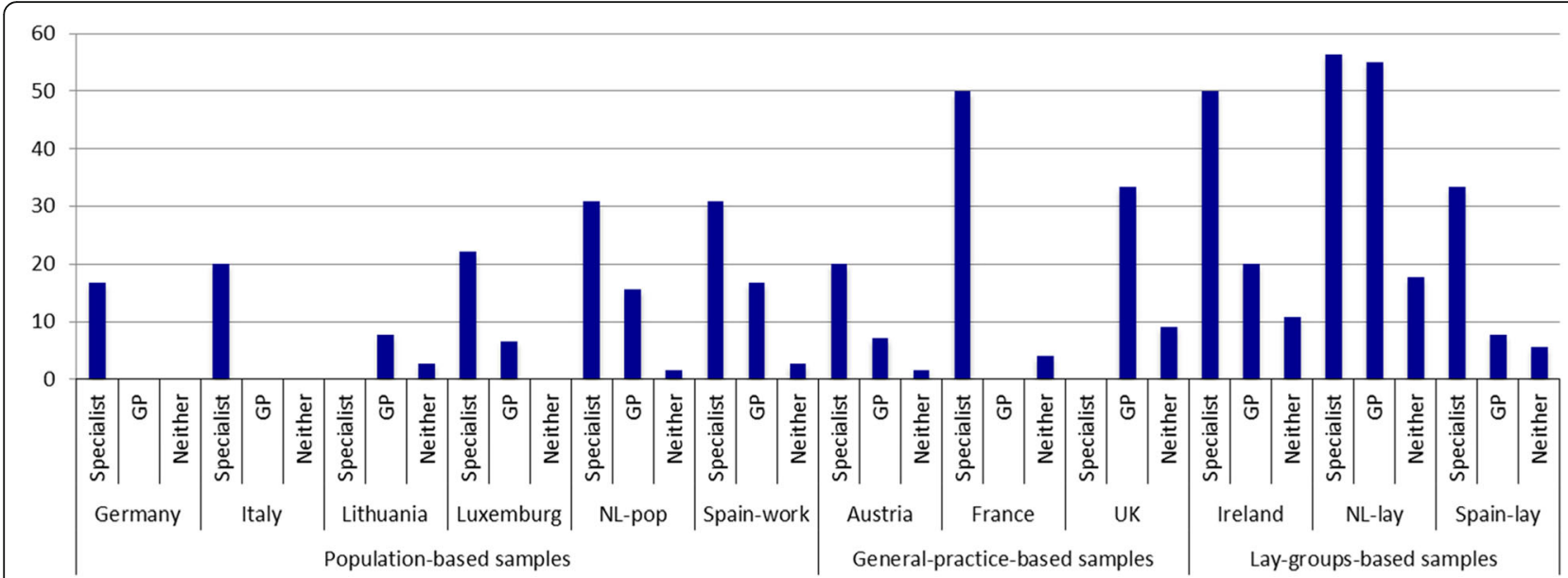

Fig. 2 Proportion (\%) of eligible participants with using migraine-preventative treatment, by country and by whom consulting. NL-pop: Netherlandspopulation; Spain-work: Spain-workplace; NL-lay: Netherlands-lay

they should be. In a resource-limited world, not everyone with migraine can receive professional health care, but neither should they: people with relatively mild and infrequent attacks who self-manage adequately with over-the-counter (OTC) remedies should not be brought into the health-care system. Published recommendations are that about $50 \%$ of people with migraine can adequately self-manage [18], suggesting that the other $50 \%$ need to consult at some level. To a large extent, need for consultation is driven by the inefficacy of the OTC medications and the need for prescription drugs. Assessed by the outcome measure sustained headache relief (SHR), arguably an adequate if imperfect outcome [19], aspirin 900-1000 $\mathrm{mg}$ has a predicted efficacy of $39 \%$ (headache relief at $2 \mathrm{~h}$ [HR] 52\%) [20] and ibuprofen $400 \mathrm{mg}$ of $45 \%$ (HR 57\%) [21]. For paracetamol $1000 \mathrm{mg}$ there are no data for SHR but HR $=56 \%$ [22].

What our findings indicate is that, even in these relatively well-resourced countries, perhaps only half of those who would be expected to benefit from physicianconsultation actually received it. Of those who did, proportions seen by GPs (9.5-18.0\% in the population-based groups) and specialists (3.1-15.0\%) were not very dissimilar. It is true that those seeing specialists might also be seeing GPs since, in such cases, we recorded only the former. But the question raised is this: is it necessary, or cost-effective, for migraine care to be thus distributed between specialists and GPs? Recommendations are that only the small minority of complicated cases should be referred from primary care to specialists $[7,18]$.

Furthermore, the quality of that care, when it was received, appeared far from perfect. If need for triptans is a reason to consult physicians, at least the majority of those doing so might be expected to receive them. While this was barely achieved (51.3\%) among those seeing specialists, only $35.9 \%$ did so from GPs. Worse, while use of preventative medication by people with $>5$ migraine days/month ought by any objective standard to be close to $100 \%$, the best we saw outside the self-selecting lay-organization members was $13.7 \%$, and this was in an employee group with, probably, facilitated access to care.

The picture is therefore not encouraging: as reflections of reach and adequacy of headache services for headache, these findings indicate depressingly poor performance in the EU. The situation may even be worse than suggested. On the subject of bias, the Eurolight project as a whole suffered from low participation proportions - on average, $27.5 \%$ in the non-lay samples [17]. Some participation bias was likely, with the probability that, through self-selection, samples were preferentially constituted of more demanding participants, whose needs and health-care utilisation were likely to be higher than average.

Several earlier studies have found much the same. In Germany, among 7431 adults, awareness of migraine was low among those who had it, as was recognition of it by health-care providers [23]. Also in Germany, in three regions of the country, a population-based study of 10,000 people found only $8 \%$ of those with migraine used triptans and only $2.3 \%$ received preventative treatment, both positively associated with socio-economic status [24] and suggesting inequitable access to health care. Similar results emerged from France: among approximately 10,000 people studied, about $60 \%$ of the 1179 with migraine were unaware of the diagnosis, only $20 \%$ used triptans and only $2.3 \%$ received preventative medication [25]. In Italy, a study of 2675 patients in 10 headache centres revealed that only $26.8 \%$ with migraine were previously correctly diagnosed, only $17.2 \%$ were using triptans and only $4.8 \%$ were using 
migraine-specific preventative medications [26]. In Sweden, a recent cross-sectional study in Stockholm analysed data from a pharmaceutical registry. It found that, of patients with a diagnosis of migraine and a high attack frequency (self-reported), and utilizing triptans for acute treatment, only $4 \%$ received preventative medication [27].

Some limitations of the study should be considered. First, Eurolight recruited from $10 \mathrm{EU}$ countries with diverse sampling methods: some samples were populationbased, others were general-practice-based and some were recruited through lay organisations [12]. A degree of interest-bias was very likely [17]. If this led to recruitment of more seriously affected patients, arguably our findings of under-treatment appear in even worse light. There was consistency in these findings, with more adequate medication among responders from lay groups, who were likely to be more vocal in their demands. Patients seeing specialists received better care than those treated by GPs, but important is that medical care was insufficient in all groups. A second limitation was that the cross-sectional Eurolight survey, while observing variations between countries, could not enquire into the reasons for under-treatment [12] (which might include differences in costs, health-seeking behaviour, culture and tradition, and structure and accessibility of healthcare systems).

The last 10 years have been crucial in improving knowledge of the prevalence and impact of migraine, beginning in 2007 with a systemic review of the existing literature [28]. The gaps in knowledge revealed by this review have been progressively filled by populationbased studies undertaken by the Global Campaign against Headache $[9,10,29]$. The GBD studies have ranked migraine as the sixth highest cause of disability worldwide, third in both men and women aged under 50 years $[4,5]$. The Eurolight study found that nearly one fifth of males and over a quarter of females with migraine reported the loss of $>10 \%$ of productive days [17]. It also demonstrated that the burden of migraine was not confined to attacks: there was measurable interictal burden also [30]. The estimated financial costs to the EU are huge [6]. Migraine remains to a very large extent to be untreated despite all this, and despite that migraine is a very treatable disorder [7, 31, 32]. This is a failure of health care with major adverse health and economic consequences.

While some access to a wider range of drugs is achieved by consulting GPs, and rather more by seeing headache specialists, this is emphatically not a call for everyone with migraine to see specialists. Rather, it is a plea to curtail the insouciance to which migraine appears condemned [8]. We identify four needs, largely to be met by education at multiple levels.
First, people with migraine should learn, through public health-education programmes, that migraine is a neurobiological disease that can often be effectively treated with correct usage of OTC drugs [7, 31, 32]. Here, pharmacists can help, but otherwise people with migraine should consult a GP. Second, in order to relieve an otherwise insupportable load on specialists, health-care providers in general and GPs in particular need better knowledge of how to recognise, diagnose and treat migraine (along with the small number of other headache disorders that are of public-health importance) $[18,32]$. Without this, the potential benefits of consulting GPs will be frustrated. This better knowledge will improve usage of available treatments, produce better outcomes, avoid wastage [33] and, importantly, reduce overall costs [7]. Third, headache services need to be structured, so that they might be delivered countrywide, efficiently and equitably to the very large number of people who stand to benefit from them [7, 18]. And fourth, and most important, is the urgent need for political recognition not only that the problem exists but also that it demands remedial action $[3,5,7]$.

The alternative is that large numbers of people will remain without diagnosis or best treatment, with not much hope for change, their unmitigated personal disability burdens translating into lost productivity with reduced societal output reflected in gross domestic product. The drive to produce new drugs and devices for headache $[34,35]$ offers little apparent utility if, when developed, they will not reach most patients [36]. The choice between these alternatives - invest in headache services, or do nothing - is, surely, not a difficult decision.

\section{Conclusion}

In wealthy European countries, too few people with migraine consult physicians, with proportionately too many of these seeing specialists, and migraine-specific medications are used inadequately even among those who do. These findings represent yet another call for action in Europe to improve care for people with headache. Education of both health-care providers and the public should be central to this action.

\section{Acknowledgements \\ Part-funding for this study was received from the European Agency for Health and Consumers of the European Commission. Financial support was also provided by Lifting The Burden. \\ We are grateful to the following who contributed to the conduct of Eurolight and/or data collection: Colette Andrée (project leader), Jose Miguel Lainez, Michel Lantéri-Minet, Daiva Rastenyte, Elena Ruiz de la Torre, Cristina Tassorelli and Lars Jacob Stovner.}

Authors' contributions

ZK, CL and TJS contributed to project design and development of the methodology. ZK and CL contributed to data acquisition. Analysis and data interpretation were performed by MM, JH and ZK. The article was drafted by 
MM and ZK and revised for intellectual content by $\mathrm{CL}, \mathrm{JH}$ and TJS. All authors reviewed and approved the final manuscript.

\section{Competing interests}

TJS and ZK are directors and trustees of Lifting The Burden, a charitable organization whose purpose, pursued in official relations with the World Health Organization, is to reduce the burden of headache worldwide. There were no conflicts of interest relating to the content of this manuscript.

\section{Publisher's Note}

Springer Nature remains neutral with regard to jurisdictional claims in published maps and institutional affiliations.

\section{Author details}

'Evangelical Hospital Unna, University of Duisburg-Essen, Essen, Germany. ${ }^{2}$ Aversi Hospital, Tbilisi, Georgia. ${ }^{3}$ Headache Medical Center, Department of Neurogeriatric Medicine and Remobilisation, Hospital of the Sisters of Charity, Linz, Austria. ${ }^{4}$ Medical Faculty, Stradins University, Riga, Latvia. ${ }^{5}$ Department of Neuromedicine and Movement Science, Faculty of Medicine and Health Sciences, NTNU Norwegian University of Science and Technology, Trondheim, Norway. ${ }^{6}$ Division of Brain Sciences, Imperial College London, London, UK.

Received: 22 November 2017 Accepted: 18 January 2018 Published online: 01 February 2018

\section{References}

1. Vos T, Flaxman AD, Naghavi M, Lozano R, Michaud C, Ezzati M, Shibuya K, Salomon JA, Abdalla S, Aboyans V, Abraham J, Ackerman I, Aggarwal R, Ahn SY, Ali MK, Alvarado M, Anderson HR, Anderson LM, Andrews KG, Atkinson C, Baddour LM, Bahalim AN, Barker-Collo S, Barrero LH, Bartels DH, Basáñez MG, Baxter A, Bell ML, Benjamin EJ, Bennett D et al (2012) Years lived with disability (YLDs) for 1160 sequelae of 289 diseases and injuries 1990-2010: a systematic analysis for the global burden of disease study 2010. Lancet 380: 2163-2196

2. Vos T, Barber RM, Bell B, Bertozzi-Villa A, Biryukov S, Bolliger I, Charlson F, Davis A, Degenhardt L, Dicker D, Duan L, Erskine H, Feigin VL, Ferrari AJ, Fitzmaurice C, Fleming T, Graetz N, Guinovart C, Haagsma J, Hansen GM, Hanson SW, Heuton KR, Higashi H, Kassebaum N, Kyu H, Laurie E, Liang X, Lofgren K, Lozano R, MacIntyre MF et al (2015) Global, regional, and national incidence, prevalence, and years lived with disability for 301 acute and chronic diseases and injuries in 188 countries, 1990-2013: a systematic analysis for the global burden of disease study 2013. Lancet 386:743-800

3. Steiner TJ, Birbeck GL, Jensen RH, Katsarava Z, Stovner LJ, Martelletti $P$ (2015) Headache disorders are third cause of disability worldwide. J Headache Pain 16:54

4. Vos T, Allen C, Arora M, Barber RM, Bhutta ZA, Brown A, Carter A, Casey DC, Charlson FJ, Chen AZ, Coggeshall M, Cornaby L, Dandona L, Dicker DJ, Dilegge T, Erskine HE, Ferrari AJ, Fitzmaurice C, Fleming T, Forouzanfar MH, Fullman N, Gething PW, Goldberg EM, Graetz N, Haagsma JA, Hay SI, Johnson CO, Kassebaum NJ, Kawashima T, Kemmer L, Khalil IA, Kinfu Y, Kyu HH, Leung J, Liang X et al (2016) Global, regional, and national incidence, prevalence, and years lived with disability for 310 diseases and injuries, 1990-2015: a systematic analysis for the global burden of disease study 2015. Lancet 388:1545-1602

5. Steiner TJ, Birbeck GL, Jensen RH, Katsarava Z, Stovner LJ, Martelletti P (2015) Headache disorders are third cause of disability worldwide. J Headache Pain 16:58

6. Linde M, Gustavsson A, Stovner LJ, Steiner TJ, Barré J, Katsarava Z, Lainez JM, Lampl C, Lantéri-Minet M, Rastenyte D, Ruiz de la Torre E, Tassorelli C, Andrée C (2012) The cost of headache disorders in Europe: the Eurolight project. Eur J Neurol 19:703-711

7. World Health Organization, Lifting The Burden (2011) Atlas of headache disorders and resources in the world 2011. Geneva: WHO

8. Katsarava Z, Steiner TJ (2012) Neglected headache: ignorance, arrogance or insouciance? Cephalalgia 32:1019-1020

9. Steiner TJ (2004) Lifting the burden: the global campaign against headache Lancet Neurol 3:204-205

10. Steiner TJ (2005) Lifting The Burden: the global campaign to reduce the burden of headache worldwide. J Headache Pain 6:373-377
11. Steiner TJ, Birbeck GL, Jensen R, Katsarava Z, Martelletti P, Stovner L (2011) The global campaign, World Health Organization and Lifting The Burden: collaboration in action. J Headache Pain 12:273-274

12. Andrée C, Stovner LJ, Steiner TJ, Barré J, Katsarava Z, Lainez JM, LantériMinet M, Mick G, Rastenyte D, Ruiz dela Torre E, Tassorelli C, Vriezen P, Lampl C (2011) The Eurolight project: the impact of primary headache disorders in Europe. Description of methods. J Headache Pain 12:541-549

13. Andrée C, Vaillant M, Barré J, Katsarava Z, Lainez JM, Lair ML, Lantéri-Minet M, Lampl C, Steiner TJ, Stovner L, Tassorelli C, Sándor PS (2010) Development and validation of the EUROLIGHT questionnaire to evaluate the burden of primary headache disorders in Europe. Cephalalgia 30:1082-1100

14. Headache Classification Subcommittee of the International Headache Society (2004) The international classification of headache disorders: 2nd edition. Cephalalgia 24(suppl 1):9-160

15. Steiner TJ, Gururaj G, Andrée C, Katsarava Z, Ayzenberg I, Yu S-Y, Al Jumah M, Tekle-Haimanot R, Birbeck GL, Herekar A, Linde M, Mbewe E, Manandhar K, Risal A, Jensen R, Queiroz LP, Scher Al, Wang SJ, Stovner LJ (2014) Diagnosis, prevalence estimation and burden measurement in population surveys of headache: presenting the HARDSHIP questionnaire. J Headache Pain 15:3

16. Stovner $L$, Al Jumah $M$, Birbeck $G L$, Gururaj $G$, Jensen $R$, Katsarava Z, Queiroz LP, Scher Al, Tekle-Haimanot R, Wang SJ, Steiner TJ (2014) The methodology of population surveys of headache prevalence, burden and cost: principles and recommendations from the global campaign against headache. J Headache Pain 15:5

17. Steiner TJ, Stovner LJ, Katsarava Z, Lainez JM, Lampl C, Lantéri-Minet M, Rastenyte D, Ruiz de la Torre E, Tassorelli C, Barré J, Andrée C (2014) The impact of headache in Europe: principal results of the Eurolight project. J Headache Pain 15:31

18. Steiner TJ, Antonaci F, Jensen R, Lainez MJ, Lanteri-Minet M, Valade D (2011) Recommendations for headache service organisation and delivery in Europe. J Headache Pain 12:419-426

19. Steiner TJ (2015) What efficacy measures are clinically relevant and should be used in Cochrane reviews of acute migraine trials? An alternative viewpoint. Cephalalgia 35:460-462

20. Kirthi V, Derry S, Moore R (2013) Aspirin with or without an antiemetic for acute migraine headaches in adults. Cochrane database of systematic reviews 30; art no CD008041. DOI: https://doi.org/10.1002/14651858. CD008041.pub3

21. Rabbie R, Derry S, Moore RA (2013) Ibuprofen with or without an antiemetic for acute migraine headaches in adults. Cochrane database of systematic reviews 30; art no CD008039. DOI: https://doi.org/10.1002/14651858. CD008039.pub3

22. Derry S, Moore R (2013) Paracetamol (acetaminophen) with or without an antiemetic for acute migraine headaches in adults. Cochrane database of systematic reviews 30; art no CD008040. DOI: https://doi.org/10.1002/ 14651858.CD008040.pub3

23. Radtke A, Neuhauser H (2012) Low rate of self-awareness and medical recognition of migraine in Germany. Cephalalgia 32:1023-1030

24. Yoon MS, Katsarava Z, Obermann M, Fritsche G, Oezyurt M, Kaesewinkel K, Katsarova A, Santowski I, Diener H, Moebus S (2012) Prevalence of primary headaches in Germany: results of the German headache consortium study. J Headache Pain 13:215-223

25. Lucas C, Géraud G, Valade D, Chautard MH, Lantéri-Minet M (2006) Recognition and therapeutic management of migraine in 2004, in France: results of FRAMIG 3, a French nationwide population-based survey. Headache 46:715-725

26. Cevoli S, D'Amico D, Martelletti P, Valguarnera F, Del Bene E, De Simone R, Sarchielli P, Narbone M, Testa L, Genco S, Bussone G, Cortelli P (2009) Underdiagnosis and undertreatment of migraine in Italy: a survey of patients attending for the first time 10 headache centres. Cephalalgia 29:1285-1293

27. Frisk P, Sporrong SK, Ljunggren G, Wettermark B, von Euler M (2016) Utilisation of prescription and over-the-counter triptans: a cross-sectional study in Stockholm, Sweden. Eur J Clin Pharmacol 72:747-754

28. Stovner LJ, Hagen K, Jensen R, Katsarava Z, Lipton R, Scher A, Steiner T, Zwart JA (2007) The global burden of headache: a documentation of headache prevalence and disability worldwide. Cephalalgia 27:193-210

29. Steiner TJ, Birbeck GL, Jensen R, Katsarava Z, Martelletti $P$, Stovner LJ (2010) Lifting The Burden: the first 7 years. J Headache Pain 11:451-455

30. Lampl C, Thomas H, Stovner LJ, Tassorelli C, Katsarava Z, Laínez JM, LantériMinet M, Rastenyte D, Ruiz de la Torre E, Andrée C, Steiner TJ (2016) 
Interictal burden attributable to episodic headache: findings from the Eurolight project. J Headache Pain 17:9

31. Evers S, Afra J, Frese A, Goadsby PJ, Linde M, May A, Sándor PS; European Federation of Neurological Societies (2009) EFNS guideline on the drug treatment of migraine-revised report of an EFNS task force. Eur J Neurol 16: 968-981

32. Steiner TJ, Paemeleire K, Jensen R, Valade D, Savi L, Lainez MJA, Diener H-C, Martelletti P, Couturier EGM (2007) European principles of management of common headache disorders in primary care. J Headache Pain 8(suppl 1): S3-S21

33. Braschinsky M, Haldre S, Kals M, lofik A, Kivisild A, Korjas J, Koljal S, Katsarava Z, Steiner TJ (2016) Structured education can improve primary-care management of headache: the first empirical evidence, from a controlled interventional study. J Headache Pain 17:24

34. Goadsby PJ, Sprenger T (2010) Current practice and future directions in the prevention and acute management of migraine. Lancet Neurol 9:285-298

35. Diener HC, Charles A, Goadsby PJ, Holle D (2015) New therapeutic approaches for the prevention and treatment of migraine. Lancet Neurol 14:1010-1022

36. Steiner TJ (2013) Headache in the world: public health and research priorities. Expert Rev Pharmacoecon Outcomes Res 14:51-57

\section{Submit your manuscript to a SpringerOpen ${ }^{\circ}$ journal and benefit from:}

- Convenient online submission

- Rigorous peer review

- Open access: articles freely available online

- High visibility within the field

- Retaining the copyright to your article

Submit your next manuscript at $\gg$ springeropen.com 